\title{
A EXECUÇÃO DAS PENAS EM ESPÉCIE: penas privativas de liberdade*
}

\author{
Luiz Alberto Machado
}

\section{A introdução.}

É-me sumamente honroso participar desta reunião, advogado e professor de província que sou. O Sérgio Pitombo, que me precedeu, certamente trouxe as luzes do seu conhecimento amadurecido sobre os grandes problemas do processo penal, cuja abordagem não pode ser feita hoje sem a participação da criminologia, cujo ensino moderno, segundo advertência de LOPEZ-REY, deve ser cometido a

“... um novo tipo de criminólogo. Para esse fim, o currículo criminólogico deve incluir a ciência política, a história, a teoria e a prática dos direitos humanos e a filosofia."l

Por outro lado, a minha responsabilidade é tanto maior - creiam-me - quanto mais se tem consciência da crise que se imputa, hoje, ao direito penal e ao processo penal. Para uma abordagem mais precisa da "execução das penas em espécies: penas privativas de liberdade", que é o tema desta nossa conversa, mister se faz, de logo, fixar algumas premissas. A primeira: o crime no seu todo é pressuposto da imposição da pena, não somente a culpabilidade. Todas as definições do direito penal conduzem a esse entendimento, bastando citar a de MEZGER que o entende como

"o conjunto de normas jurídicas que regulam o poder punitivo do Estado, ligando ao delito, como pressuposto, a pena, como conseqüência."

Mas o que é o crime? Eu o vejo como uma ação típica e censurável. O crime é, essencialmente, ação, compreendido tanto o facere como o non facere, tanto a ação como a omissão; mas, sobre essa ação em sentido amplo devem recair os atributos de tipicidade e de censurabilidade. Sem maiores * Palestra proferida pelo Professor Titular LUIZ ALBERTO MACHADO, da Faculdade de Direito da UFPR, na Procuradoria Geral do Estado de São Paulo no dia 25 de agosto de $1987,17: 30$ horas.

1 Manifesto Criminológico, Revista de Direito Penal n²4, p. 16.

Revista da Faculdade de Direito da UFPR, Curitiba, a. 29, n. 29, 1996, p.111-119 
delongas: ao tipo concorrem tanto o seu asppecto formal - a concretização aparente da conduta modelo - como o seu aspecto material - a inexistência de causas descriminantes. O tipo, no seu todo, realiza a existência da conduta como subsumida no modelo da conduta como agressora do Direito.

De outra parte, o Estado de direito democrático assume maiores compromissos com o chamado (e ainda não alcançado) direito penal da culpa - nullum crimen sine culpa - oriundo já do Código Criminal do Império, cujo art. $3^{\circ}$ dispunha que

"Não haverá criminoso ou delinqüente sem má-fé, isto é, sem conhecimento do mal e intenção de o praticar."

e consagrado no C. penal atual no art. 19, ainda que, a meu ver, com redação defeituosa:

"Pelo resultado que agrava especialmente a pena, só responde o agente que o houver causado ao menos culposamente."

O fracasso do psicologismo, que limitava a culpabilidade ao dolo e à culpa em sentido escrito, fez surgir o primeiro conceito normativo de culpabilidade. REINHARD FRANK estabeleceu que a culpabilidade comportava a imputabilidade, o elemento psicológico-normativo de BRUNO (dolo e a culpa em sentido estrito) e a exigibilidade de conduta adequada à norma. $\mathrm{O}$ dolo, porém, ainda era o dolus malus, herança do direito romano, portanto o atual conhecimento do ilícito. Como evolução dessa teoria extrema do dolo, preferida dos causalistas, criou-se a teoria da culpabilidade extremada, dos finalistas, mero juízo puro de censura possível à conduta: imputabilidade, potencial conhecimento do ilícito e exigibilidade de conduta adequada ao direito. Esse antagonismo das duas correntes, a da teoria extrema do dolo, dos causalistas, fazendo-o portar o atual conhecimento do ilícito, e a da culpabilidade extremada, dos finalistas, retirando o dolo da estrutura da culpabilidade, colocando-o no tipo (o tipo subjetivo) e deixando, para a culpabilidade, não mais o atual, mas o potencial conhecimento do ilícito (cegueira jurídica, de MEZGER, opção vital, de BOCKELMANN), fez surgir uma de compromisso, de construção pretoriana, a da culpabilidade limitada: o dolo continua na estrutura da culpabilidade mas, em lugar do atual, porta o potencial conhecimento do ilícito.

$\mathrm{Na}$ verdade, a culpa é censura. Ao direito penal não compadecem sentimentos pessoais, ínsitos no conceito de culpa, mas critérios de censura 
do administrado que, sabendo e podendo agir de forma diferente, não o faz. A culpabilidade, pois, é uma censurabilidade que se aplica ao capaz de culpa, com potencial conhecimento do ilícito e que atuou em condições que se lhe podia exigir um comportamento diferente, vale dizer um comportamento adequado ao direito. E se, pela ótica do direito penal - como ciência normativa, do dever-ser, que utiliza um método dedutivo lógico jurídico - abstrato não pode construir princípios e conceitos que comportem exceções - a conduta típica e censurável completa o crime, a pena só pode ser uma pena retributiva.

\section{Fins da pena: retribuição e readaptação.}

Esta a segunda premissa. Por um erro filosófico, sempre se cometeu ao direito penal a responsabilidade quase única de combater as condutas desviantes; a cada vez que a delinqüência recrudesce, intensificam-se as acusações de fracasso do direito penal. Hoje vive-se uma época em que o aperfeiçoamento das formas criminosas sutis, galgando as elites sócio-econômicas, e o concomitante e assustador aumento da criminalidade violenta atraem a atenção dos dirigentes e dos estudiosos e recaem sobre o princípio constitucional da isonomia jurídica e sobre o direito penal como afirmações da sua falência. A responsabilização do direito penal é, porém, absolutamente inválida; como ciência normativa do dever-ser, ancorada a um conceito de apenação pela culpabilidade (entendida como reprovabilidade, censurabilidade da conduta), só lhe cabe o punir, o castigar o agente pela sua atuação desviante; se essa retribuição alcança a prevenção do crime ou a readaptação do criminoso (fatores finalísticos de consideração secundária para o direito penal), tanto melhor. $\mathrm{Na}$ verdade, o fim primordial do direito penal é exatamente - enquanto subordinada a imposição da pena à culpa do autor - retribuição e ou castigo. Outro não é o entendimento de LOPEZ-REY:

"Enquanto subsistam os sistemas de justiça penal, sua ratio essendi e a do direito penal não é a correção, a ressocialização ou a reabilitação do delinqüente, mas, sim, a justiça social." ${ }^{2}$

Da mesma forma BETTIOL, com toda a ênfase latina da sua incontestável autoridade, ao tratar do "direito penal do comportamento

2 Manifesto Criminológico, Revista de Direito Penal n²4, p. 16.

Revista da Faculdade de Direito da UFPR, Curitiba, a. 29, n. 29, 1996, p.111-119 
interior", uma reformulação avançada do "direito penal da vontade" da Escola de Kiel, de que foram expoentes SCHAFF STEIN e DAHM, acentuou:

"Nessuno pensa a toccare o a rovesciare la correlazione fatto-reato, reato-retribuzione, retribuzione-pena per negare o scambiare i termini tra di loro." 3

É evidente que o direito penal assentado na censurabilidade da conduta típica não compatibiliza a pena, ao menos no momento da sua aplicação, com a idéia de prevenção, mas a entende como retribuição ética da conduta. A pena imposta a quem tem a capacidade de entender e de querer, isto é, a pena imposta em conseqüência da censurabilidade da conduta só pode ser retributiva. SOLÉR mostrou que a pena é ameaça e é castigo: em nenhuma hipótese se pode prometer ao criminoso, pelo crime, uma vantagem. A pena é imposta pelo que o autor censurável fez, não pelo que é. Ao direito penal, sancionador em sentido lógico, é reservado, pelo ordenamento jurídico, a sanção retributiva. SOLÉR, ao dividir as sanções em três categorias - repositivas, reparativas e retributivas - reserva estas para o direito penal.

Não se esconda que ROXIN nega, à pena, esse caráter de retribuição, entendendo-o cientificamente insustentável e político-criminalmente danoso; após afirmar que

"a teoria da retribuição tampouco é aceitável, porque sua premissa, de que o injusto cometido pelo agente é compensado e saldado pela pena retrubutiva, é irracional e incompatível com os fundamentos estatais da Democracia." 4 ,

negando à censurabilidade a incapacidade de fundamentar, em concreto, a qualidade e a quantidade de pena -

"é impossível trabalhar com o conceito de culpabilidade."

-, ROXIN propõe a manutenção do critério de censurabilidade para fixação do máximo da pena.

3 Estado de Direito e Gesinnungsstrasfrecht, Revista de Direito Penal n ${ }^{\circ} 15 / 16$, p. 11.

4 CLAUS ROXIN, A culpabilidade como critério limitador da pena, Revista de Direito Penal 11/12, p. 8.

5 A culpabilidade como critério limitador da pena, Revista de Direito Penal 11/12, p. 7. 
Ora, se a censurabilidade não pode ser mensurada - salvo por um ato de fé fundado numa suposição metafísica, no dizer de $\operatorname{ROXIN}^{6}$ - para mensurar uma quantidade de pena, não o pode para fixar um máximo: se a censurabilidade é imensurável, é imensurável e ponto final pois que não pode, ao mesmo tempo, ser e não ser. $O$ erro fundamental parece-me localizar-se na crença de que a pena, por ser um mal, anula o mal do crime. Essa avelhantada teoria algébrica dos negativos que, multiplicados, produzem o positivo, não se coaduna com o Estado de direito moderno pois, neste, a pena assenta-se na legalidade da defesa contra o crime, eticamente limitada: o Estado, pelo princípio da legalidade, só pode fazer o que a lei expressamente o autoriza; aqui o fundamento constitucional da parte especial do c. penal. A pena é imposta como castigo, como retribuição, como censura pelo cometimento do crime.

Daí porque correta a idéia de que

"a teoria retributiva deve constituir o ponto de partida na concepção da pena."

CURY completa o seu raciocínio afirmando:

"Em condições ideais, a sanção punitiva deveria ser hábil para atender à ressocialização total do acusado."

Desde que se inicia o ensino do direito penal, diz-se que um dos seus caracteres é ser igualitário. Vale, porém, a afirmação de ALESSANDRO BARATTA, de que o direito penal é, por excelência, um direito desigual. ${ }^{9}$ DISRAELI afirmou que a história do sistema punitivo é a história das relações entre duas nações: a dos ricos e a dos pobres. ${ }^{10}$

Inegável a razão de DAHRENDORF ao falar em sociedade dividida; ${ }^{1 P}$ isto é, a divisão da sociedade em duas partes. E, nessa divisão, apenas a parte social composta pelas classes alta e média produz os juízes e os legisladores, que terão como paradigma das suas atividades os componentes da outra parte social, a dos pobres (terceiro estrato,

6 A culpabilidade como critério limitador da pena, Revista de Direito Penal 11/12, p. 9.

7 ENRIQUE CURY, Contribuição ào estudo da pena, Revista de Direito Penal 11/12, p. 24.

8 Contribuição ao estudo dà pena, Revista de Direito Penal 11/12, p. 25.

9 Criminologia Crítica e Política Penal Alternativa, Revista de Direito Penal 23, p.7/21.

10 ALESSANDRO BARATTA, Marginalidade social e justiça, Revista de Direito Penal 21/22, p. 5.

11 Deutsche Richter, p. 76 e ss.

Revista da Faculdade de Direito da UFPR, Curitiba, a. 29, n. 29, 1996, p. 111-119 
assalariados de baixa renda, e quarto estrato ou pobreza absoluta ou marginalidade social ou população marginal). Vale dizer, os legisladores estarão visando a outra sociedade para a confecção das condutas proibidas, que consideram desviantes da normalidade da sua sociedade, e cominação em abstrato das suas sanções, enquanto os juízes, ao julgarem as condutas típicas, estarão visando conter, dentro da outra sociedade, os que a ela pertencerem.

Neste passo, forçoso é reconhecer-se que quanto mais se desce na escala social, mais as redes da malha da tipificação penal apertam-se, afinam-se, de forma a impedir que os "desviantes" da outra sociedade, da classe baixa e da classe marginal, logrem a mesma facilidade de escapar da punição que têm aqueles do colarinho branco (ou da gravata preta), isto é, das classes alta e média.

Desde a escolha dos tipos que comporão o elenco fragmentário do direito penal, na sua elaboração abstrata, as possibilidades de não punição dos delinqüentes violentos do white collar são muito maiores. Haverá sempre a possibilidade de afirmação de que atuaram com uma excludente de criminalidade ou com uma causa de exculpação, máxime se a vítima provier de camadas sociais mais baixas.

O mecanismo de investigação e de aplicação das sanções penais é muito mais complexo, traumatizante e propício à estigmatização das classes baixa e marginal, sob a fantasia do processo de conhecimento condenatório penal, que se instaura após inquérito policial, ainda que evidente qualquer das causas de exclusão da criminalidade (atipicidade material da conduta). NILO BATISTA $^{12}$ já alertou para a atividade descriminalizadora ilegal da polícia, quando compõe com ofensor e vítima, ainda que ofendido bem jurídico indisponível (vida, integridade física) ou quando faz desaparecer todos os vestígios da infração ou autoria que, por quaisquer interesses, não lhe interessa investigar, ou, ainda, quando monta um inquérito para a absolvição do acusado de conduta desviante; essa ilegal atuação descriminalizadora da polícia é de tal forma disseminada que, pode-se dizer, faz parte do dia-a-dia da sua atividade.

Ainda nesse aspecto policial, as prisões sem causa ou por mera suspeita, colocando o indivíduo em contato com a população carcerária de

12 Algumas palavras sobre a descriminalização, Revista de Direito penal 13/14, p.28/40. 
tal forma que o marca e o obriga a uma opção delinqüencial. Vale ressaltar o depoimento contido na revista ISTOÉ n. 124, de 09 de maio de 1979, prestado por um desviant condenado e foragido:

"Agora, existe também muita covardia, tem bandido que chama o rapaz para conversar perto do banheiro. Aí seus colegas chegam e dão uma dura, uma gravata no cara. Aí todos caem dentro. Perdeu a moral uma vez, vai perder mais vezes. Só não acontece isso quando o garoto é macho mesmo e mata os seus violentadores. Mas mesmo assim ele cedeu e fica sempre prejudicado na cadeia. Acho isso errado. A revolta começa aí: como é que um homem criado por sua família como homem pode perder a hombridade lá dentro? Sabe o que é uma mulher ir visitar o malandro e saber, no pátio de visitas, que ele tá levando porrada a granel e está deitando debaixo de outro homem? Então, ela abandona o cara, que fica numa situação difícil na cadeia. Aí vira bicha mesmo, para sobreviver." ${ }^{13}$

A atividade judicial é, por seu lado, altamente aleatória no direito penal; como os juízes provêm de uma parte da sociedade, julgam com maior rigor os da outra parte e com menor rigor os da sua parte, inclusive os policiais violentos; a estes socorre o fato de que uma boa parcela da população aceita e até mesmo aplaude as manifestações violentas da polícia (um agente socialmente sancionado). Acresça-se que os componentes das classes média e alta, econồmica e financeiramente estáveis e fortes, possuem condições de contratação de advogados de tal forma hábeis, que sempre lhes fica mais fácil o enfrentamento de um tedioso, moroso e caro processo judicial, ao fim do qual recebem a sentença absolutória que lhes garante, oficialmente, o reconhecimento da sua probidade ou da sua atuação conforme o direito.

Vale referir à importação, pelo processo penal do civil, do conceito de direito abstrato de agir; isto é, tem-se ação ainda quando não se tenha o direito material. Ora, no processo penal deve viger, como corolário da isonomia jurídica, o princípio da presunção de inocência, pois que o processo penal, já se disse, começa punindo para saber se se deve punir. Portanto, a ação penal deve se conter dentro do conceito de direito concreto, sob pena de o agente do parquet estar cometendo abuso de autoridade, quando a sua denúncia não se embasa em sólidas provas materiais e indiciação de autoria. 


\section{Execução das penas privativas de liberdade.}

Hoje temos, no tocante ao mecanismo de execução das penas privativas de liberdade, a Lei de Execução Penal, que tomou o n. 7.210, de 11 de julho de 1984. E desde logo fixa o caráter jurisdicional da execução, no seu art. $2^{\circ}$. Não cabe instaurar, nesta conversa, uma discussão sobre o conceito carnelutiano de jurisdição aplicado ao processo penal: o que importa, menos do que cientificamente falar-se em jurisdicionalização da execução, é dizer-se que a ela devem acudir, com evidente grano salis, os princípios da legalidade e da tipicidade cuidados por Juiz e que, exatamente por serem princípios, como diz GORDILLO, impõem-se até sobre normas positivas. E, esses, além de tudo, são princípios constitucionais.

Verdade que a crise da prisão e do sistema penitenciário, em verdadeiro estado falimentar à espera de um síndico para gerir a sua massa falida, reflete-se sobre o delinqüente como instrumento de opróbrio, representando uma verdadeira pós-graduação no crime, após o que nenhuma oportunidade de regeneração lhe será concedida, mesmo porque

“'Criminoso' é, efetivamente, na opinião pública, quem esteve sujeito a sanções estigmatizantes e isto significa, na prática, quem é ou foi parte da população carcerária." 14

Vale, ainda, a entrevista a ISTOÉ:

"Não gosto muito de ser bandido, mas tenho poucas condições de sair dessa vida." $" 15$

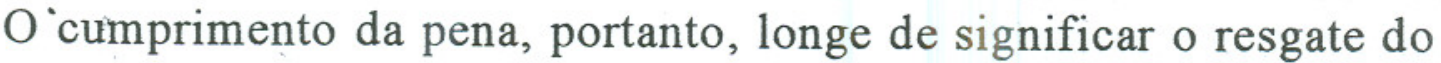
preço do crime, é o estigma indelével que o desviant carrega pela vida toda.

Atenta a que a individualização da pena privativa de liberdade permeia os momentos de cominação, de aplicação e de execução, a lei criou os regimes aberto, semi-aberto e fechado (o primeiro, antiga experiência no Estado de São Paulo) para o cumprimento das penas privativas de liberdade. Estabeleceu, ainda, a progressão (art. 112), vale dizer, a escalada de um regime mais rigoroso para outros menos rigorosos. Mas, atenta à individualização executória da pena, permite a regressão, isto é, o caminho inverso: a vinda de um regime menos rigoroso para um mais rigoroso (art.

14 ALESSANDRO BARATTA, Criminologia crítica e política penal alternativa, Revista de Direito Penal 23,p. 10 .

15 P. 56 
118). Uma das formas de individualização da pena na sua fase executiva é o livramento condicional, previsto nos arts. 131 usque 146.

Autorizações de saída: permissão de saída e saída temporária (art. 120 e seguintes).

Remição: o trabalho como direito do condenado (art. 31).

A conversão (art. 180 e 183).

$115) ?$

Regime inicial aberto: juízo de conhecimento ou de execução (art.

\section{A conclusão}

Dito o que, creio que devo encerrar e permito-me fazê-lo parafraseando o alerta de LOPEZ-REY:

“... se o direito penal deseja sobreviver, deve-se dar conta de que a criminalidade convencional não é mais do que um aspecto do fenômeno sócio-político da criminalidade, que os países em desenvolvimento devem ser estimulados a desenvolver seus próprios enfoques, ao invés de imitar os que existem em países muito diferentes em que o estudo da criminalidade não convencional, exige um enfoque que o direito penal contemporâneo não pode dar." 16

Estas as reflexões e as perplexidades que achei do meu dever trazer a esta palestra.

Muito obrigado.

16 Manifesto criminológico, Revista de Direito Penal 24.

Revista da Faculdade de Direito da UFPR, Curitiba, a. 29, n. 29, 1996, p.111-119 